Design of Mega-Voltage X-ray Digital Radiography and Computed Tomography Performance Phantoms

M. B. Aufderheide, H. E. Martz, M. Curtin

June 29, 2009 
This document was prepared as an account of work sponsored by an agency of the United States government. Neither the United States government nor Lawrence Livermore National Security, LLC, nor any of their employees makes any warranty, expressed or implied, or assumes any legal liability or responsibility for the accuracy, completeness, or usefulness of any information, apparatus, product, or process disclosed, or represents that its use would not infringe privately owned rights. Reference herein to any specific commercial product, process, or service by trade name, trademark, manufacturer, or otherwise does not necessarily constitute or imply its endorsement, recommendation, or favoring by the United States government or Lawrence Livermore National Security, LLC. The views and opinions of authors expressed herein do not necessarily state or reflect those of the United States government or Lawrence Livermore National Security, LLC, and shall not be used for advertising or product endorsement purposes.

This work performed under the auspices of the U.S. Department of Energy by Lawrence Livermore National Laboratory under Contract DE-AC52-07NA27344. 


\title{
Design of Mega-Voltage X-ray Digital Radiography and Computed Tomography Performance Phantoms
}

\author{
Maurice B. Aufderheide, Harry E. Martz, Jr., \\ Lawrence Livermore National Laboratory \\ Livermore, CA 94551 \\ and \\ Michael Curtin \\ Parsons Corporation \\ Arlington, VA 22209
}

Work performed on the Defense Nuclear Detection Office of the

Department of Homeland Security

Statement of Work

IAA No. HSHQDC-08-X-00388

June 26, 2009

LLNL-TR- 414301

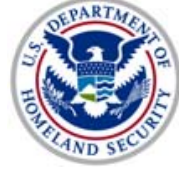




\title{
Design of Mega-Voltage X-ray Digital Radiography and Computed Tomography Performance Phantoms
}

\author{
Maurice B. Aufderheide, Harry E. Martz, Jr., \\ Lawrence Livermore National Laboratory \\ Livermore, CA 94551 \\ and \\ Michael Curtin \\ Parsons Corp \\ Arlington, VA 22209
}

\section{Executive Summary}

A number of fundamental scientific questions have arisen concerning the operation of high-energy DR and CT systems. Some of these questions include:

1. How deeply can such systems penetrate thickly shielded objects?

2. How well can such systems distinguish between dense and relatively high $Z$ materials such as lead, tungsten and depleted uranium and lower $\mathrm{Z}$ materials such as steel, copper and tin?

3. How well will such systems operate for a uranium material which is an intermediate case between low density yellowcake and high density depleted uranium metal?

These questions have led us to develop a set of phantoms to help answer these questions, but do not have any direct bearing on any smuggling concern. These new phantoms are designed to allow a systemic exploration of these questions by gradually varying their compositions and thicknesses. These phantoms are also good probes of the blurring behavior of radiography and tomography systems.

These phantoms are composed of steel ( $\rho$ assumed to be $7.8 \mathrm{~g} / \mathrm{cc}$ ), lead ( $\rho$ assumed to be $11.4 \mathrm{~g} / \mathrm{cc}$ ), tungsten ( $\rho$ assumed to be $19.25 \mathrm{~g} / \mathrm{cc}$ ), uranium oxide $\left(\mathrm{UO}_{3}\right)$ ( $\rho$ assumed to be $4.6 \mathrm{~g} / \mathrm{cc}$ ), and depleted uranium (DU) ( $\rho$ assumed to be $18.9 \mathrm{~g} / \mathrm{cc}$ ). There are five designed phantoms described in this report:

1. Cylindrical shells of Tungsten and Steel;

2. Depleted Uranium Inside Tungsten Hemi-cube Shells;

3. Nested Spherical Shells;

4. $\mathrm{UO}_{3}$ Cylinder; and a

5. Shielded DU Sphere. 


\section{Introduction and Motivation}

The Department of Energy (DOE), Department of Defense (DoD) and Department of Homeland Security's (DHS) are developing large format X-ray Digital Radiography (DR) and Computed Tomography (CT) Systems. These systems are used to inspect materials, sub-assemblies, full-up assemblies and cargo. Examples include inspecting weapons systems for correct assembly as well as for identification of defects and cargo to find contraband (e.g., currency and drugs), Special Nuclear Materials (SNM) and nuclear weapons. The DHS cargo X-ray DR systems are usually referred to as Non-Intrusive Inspection (NII) systems some of which use dual-energy (6 and 9 MV) bremsstrahlung $X$-ray sources and detectors to distinguish between high atomic number, $Z,(Z>72)$ and lower $\mathrm{Z}(\mathrm{Z}<72)$ materials.

A number of fundamental scientific questions have arisen concerning the operation of high-energy DR and CT systems. Some of these questions include:

4. How deeply can such systems penetrate thickly shielded objects?

5. How well can such systems distinguish between dense and relatively high $Z$ materials such as lead, tungsten and depleted uranium and lower $\mathrm{Z}$ materials such as steel, copper and tin?

6. How well will such systems operate for a uranium material which is an intermediate case between low density yellowcake and high density depleted uranium metal?

These questions have led us to develop a set of phantoms to help answer these questions, but do not have any direct bearing on any smuggling concern. These new phantoms are designed to allow a systemic exploration of these questions by gradually varying their compositions and thicknesses. These phantoms are also good probes of the blurring behavior of radiography and tomography systems.

These phantoms are composed of Steel ( $\rho$ assumed to be $7.8 \mathrm{~g} / \mathrm{cc}$ ), Lead ( $\rho$ assumed to be $11.4 \mathrm{~g} / \mathrm{cc}$ ), Tungsten ( $\rho$ assumed to be $19.25 \mathrm{~g} / \mathrm{cc}$ ), Uranium Oxide $\left(\mathrm{UO}_{3}\right)$ ( $\rho$ assumed to be $4.6 \mathrm{~g} / \mathrm{cc}$ ), and depleted Uranium (DU) ( $\rho$ assumed to be $18.9 \mathrm{~g} / \mathrm{cc}$ ).

In this document, we will describe the phantoms and explain the motivation for developing them.

\section{Phantom 1: Cylindrical shells of Tungsten and Steel}

This phantom is a set of cylindrical shells $30-\mathrm{cm}$ long. The innermost cylinder has a radius of $1.5 \mathrm{~cm}$, surrounded by outer layers 1-, 2- and 3-cm thick. Each piece can be steel or tungsten. This phantom can be composed of any mixture of these materials, and any layer or combination of layers can be used in any combination, depending on the spatial resolution and the penetration of the radiographic system of interest. When all layers are used, steel end caps of radius $7.5 \mathrm{~cm}$ and height $5 \mathrm{~cm}$ are used at the top and bottom of the phantom. 
In Figure 1 we display a cutaway of an instance of Phantom 1 (P-1). This instance is cylindrical shells of Tungsten and Steel, in which the central layer is tungsten, followed by steel, then tungsten, with an outer layer of steel and steel end caps. The P-1 steel and tungsten radii, volumes, and mass are given in Table 1.

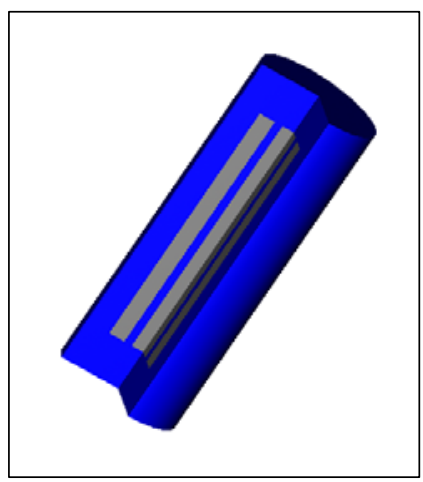

Figure 1. Cutaway schematic of one example of Phantom 1: Cylindrical shells of Tungsten and Steel. Blue is steel and gray is tungsten.

Table 1. Phantom 1 radii, volumes, and mass of the two materials steel and tungsten.

\begin{tabular}{|l|c|c|c|c|c|c|}
\hline Name & $\begin{array}{c}\text { Inner } \\
\text { radius } \\
(\mathbf{c m})\end{array}$ & $\begin{array}{c}\text { Outer } \\
\text { radius } \\
\mathbf{( c m )}\end{array}$ & $\begin{array}{c}\text { Cylinder wall } \\
\text { thickness } \\
\mathbf{( c m )}\end{array}$ & $\begin{array}{c}\text { Volume } \\
\mathbf{( c m}^{\mathbf{3}} \mathbf{)}\end{array}$ & $\begin{array}{c}\text { Steel } \\
\text { Mass } \\
\mathbf{( k g )}\end{array}$ & $\begin{array}{c}\mathbf{W} \\
\text { Mass } \\
(\mathbf{k g})\end{array}$ \\
\hline Center & -1. & 5 & - & 212.1 & 1.65 & 4.08 \\
\hline $\mathbf{1}^{\text {st }}$ can & 1.52. & 5 & 1 & 377.0 & 2.94 & 7.26 \\
\hline $\mathbf{2}^{\text {nd }}$ can & 2.54 & .5 & 2 & 1319 & 10.3 & 25.4 \\
\hline $\mathbf{3}^{\text {rd }} \mathbf{c a n}$ & 4.57 & .5 & 3 & 3393 & 26.5 & 65.3 \\
\hline Caps & -- & -------- & - & 1767 & 13.8 & ------ \\
\hline Total & --- & -------- & - & ----- & 55.2 & 116 \\
\hline
\end{tabular}

This phantom has a number of uses. First, the individual shells can be used for determining the modulation transfer function for digital radiography and computed tomography. Second, this phantom with alternating cans or layers could be used as a step wedge calibration phantom and as a test of radiographic penetration. Last, instances of this phantom with alternating layers can be used as a test of material identification. 


\section{Phantom 2: Depleted Uranium Inside Tungsten Hemicube Shells}

Phantom 2 is a $3-\mathrm{cm}$ radius sphere of depleted uranium surrounded by a set of tungsten hemi-cube shells (hollow cubes) of outer cube size on a side of 10.6-, 15.6- and 20.6-cm. The inside diameter of the first hemi-cube shell is $6.2 \mathrm{~cm}$ (including $1 \mathrm{~mm}$ air gap for clearance on each side). The user has the choice of how many of the 3 hemi-cube shells to use. A cutaway schematic of P-2 with all 3 hemi-cube shells in place is shown in Figure 2. P-2 hemi-cube shell dimensions, volumes, and masses are given in Table 2.

This phantom is designed to be a "uniform contrast" between the two materials DU and $\mathrm{W}$, that is, there is very little difference in density between the DU and surrounding tungsten. The layers of tungsten are added to test the discrimination between uranium and tungsten with increasing phantom thickness.

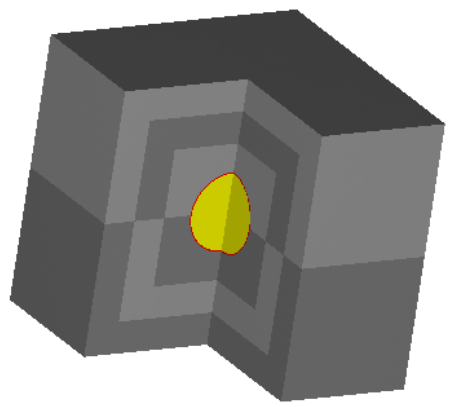

Figure 2. Cutaway schematic of one example of Phantom 2: Depleted Uranium inside Tungsten Box. Depleted uranium is yellow, air is red and tungsten is dark or light gray, in order to distinguish individual hemi-cube shells.

Table 2. Phantom 2 DU sphere radius, cube shell dimensions, volumes, and masses.

\begin{tabular}{|l|c|c|c|c|c|}
\hline \multicolumn{1}{|c|}{ Name } & $\begin{array}{c}\text { Radius } \\
\mathbf{( c m )}\end{array}$ & $\begin{array}{c}\text { Wall } \\
\text { thickness } \\
(\mathbf{c m})\end{array}$ & $\begin{array}{c}\text { Outer dimension } \\
\text { of cube } \\
\mathbf{( c m )}\end{array}$ & $\begin{array}{c}\text { Volume } \\
\left(\mathbf{c m}^{\mathbf{3}}\right)\end{array}$ & $\begin{array}{c}\text { Mass } \\
\mathbf{( k g )}\end{array}$ \\
\hline U Sphere & 3 & & & 113.1 & 2.14 \\
\hline Cube shell 1 & 2 & .2 & 10.6 & 1066 & 20.5 \\
\hline Cube shell 2 & 2 & .5 & 15.6 & 2605 & 50.2 \\
\hline Cube shell 3 & 2 & .5 & 20.6 & 4945 & 95.2 \\
\hline Total & -- & ------- & & ---- & 168.0 \\
\hline
\end{tabular}




\section{Phantom 3: Nested Spherical Shells}

Phantom 3 is a set of nested spherical shells around a solid inner sphere, all of which can be composed of a variety of materials. The sphere has a radius of $1.5 \mathrm{~cm}$ and can be depleted uranium or tungsten. The second layer is a shell composed of DU, tungsten or lead with inner radius of $1.6 \mathrm{~cm}$ and a thickness of $1.4 \mathrm{~cm}$. The last three spherical shells extend the outer diameters to 4,7 and $10 \mathrm{~cm}$ and can be tungsten or lead. Any subset of these phantoms can also be used. A cutaway schematic view of one instance of P-3 is shown in Figure 3, where the compositions of the layers are depleted uranium, tungsten, lead, tungsten and lead, from the center outward. Table 3 lists the properties of P-3.

This phantom has a number of uses. First, the individual shells can be used for determining the modulation transfer function for digital radiography and computed tomography. Second, this phantom with alternating layers can also be used as a step wedge calibration phantom and as a test of radiographic penetration. Last, instances of this phantom with alternating layers can be used as a test of material identification.

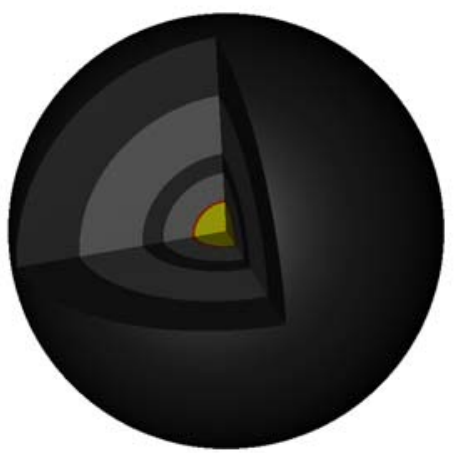

Figure 3. Cutaway schematic of one example of Phantom 3: Nested Spherical Shells. DU is yellow, tungsten is light gray and lead is black. Sphere and shell properties are given in Table 3.

Table 3. Phantom 3 radii, volumes, and mass of the two materials steel and tungsten.

\begin{tabular}{|l|c|c|c|c|c|c|c|}
\hline Name & $\begin{array}{c}\text { Inner } \\
\text { radius } \\
(\mathbf{c m})\end{array}$ & $\begin{array}{c}\text { Outer } \\
\text { radius } \\
(\mathbf{c m})\end{array}$ & $\begin{array}{c}\text { Shell } \\
\text { thickness } \\
(\mathbf{c m})\end{array}$ & $\begin{array}{c}\text { Volume } \\
\mathbf{( c m}^{\mathbf{3}} \mathbf{)}\end{array}$ & $\begin{array}{c}\text { DU Mass } \\
\mathbf{( k g )}\end{array}$ & $\begin{array}{c}\text { W Mass } \\
\mathbf{( k g )}\end{array}$ & $\begin{array}{c}\text { Pb } \\
\mathbf{M a s s} \\
\mathbf{( k g})\end{array}$ \\
\hline Sphere & -1. & 5 & & 14.1 & 0.266 & 0.271 & --------- \\
\hline $\mathbf{1}^{\text {st }}$ shell & 1.5 & 3 & 1.4 & 95.91. & 811. & 85 & 1.09 \\
\hline $\mathbf{2}^{\text {nd }}$ shell & 34 & & 1 & 155 & ------- & 2.98 & 1.77 \\
\hline $3^{\text {rd }}$ shell & 4 & 7 & 3 & 1169 & ------ & 22.5 & 13.3 \\
\hline $\mathbf{4}^{\text {th }}$ shell & 71 & 0 & 3 & 2752 & ------ & 53.0 & 31.4 \\
\hline
\end{tabular}




\section{Phantom 4: $\mathrm{UO}_{3}$ Cylinder}

Phantom 4 is a cylinder of $\mathrm{UO}_{3}$ powder with radius of $8.9 \mathrm{~cm}$, a height of $17.8 \mathrm{~cm}$ and density of $\sim 4.6 \mathrm{~g} / \mathrm{cm}^{3}$. The $\mathrm{UO}_{3}$ powder cylinder is inside a $1 / 4$ " thick crimped stainless steel can. A cutaway view is shown in Figure 4. The volume of the powder cylinder is $4429.5 \mathrm{~cm}^{3}$ with a mass of $20.4 \mathrm{~kg}$. The steel can has a volume of $1017.3 \mathrm{~cm}^{3}$ and a mass of $7.9 \mathrm{~kg}$.

This phantom is designed to test high $\mathrm{Z}$ material identification for a uranium compound with density between that of yellowcake and metallic depleted uranium.

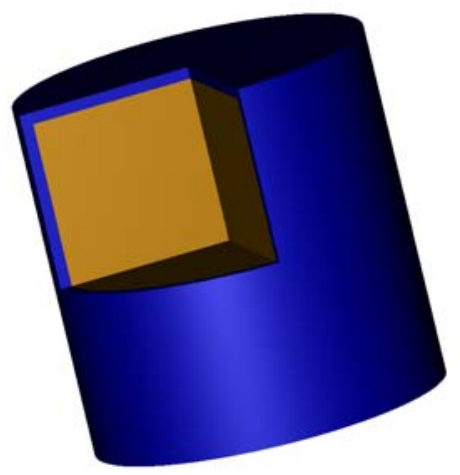

Figure 4. Cutaway schematic view of Phantom 4: $\mathrm{UO}_{3}$ Cylinder. $\mathrm{UO}_{3}$ is orange-yellow, steel blue.

\section{Phantom 5: Shielded DU Sphere}

Phantom 5 is a sphere of DU with an outer radius of $4.1 \mathrm{~cm}$. An optional central hole with radius $1.5 \mathrm{~cm}$ can also be used, resulting in a spherical shell with thickness $2.6 \mathrm{~cm}$. This sphere or shell is surrounded by a lead cubic shell $3 \mathrm{~cm}$ thick with an outer length, width and height of $15.8 \mathrm{~cm}$. This shell is surrounded by a steel cubic shell $0.6 \mathrm{~cm}$ thick with an outer length, width and height of $17 \mathrm{~cm}$. A cutaway view is shown in Figure 5, with the central hole. The mass of the DU shell is $5.19 \mathrm{~kg}$; the mass of the lead cubical shell is $34.23 \mathrm{~kg}$; the mass of the steel shell is $7.56 \mathrm{~kg}$. The total mass of the phantom is $46.98 \mathrm{~kg}$.

This phantom is designed to determine the modulation transfer function for digital radiography and computed tomography of the DU spherical shell, when heavily shielded by a $3 \mathrm{D}$ cubical lead shell. 


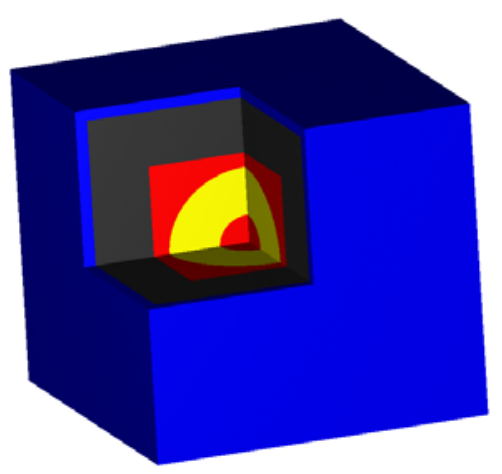

Figure 5. Cutaway schematic view of Phantom 5: DU sphere inside a Pb box, clad in steel. The DU is yellow, Pb is black, Steel is blue and air is red. 